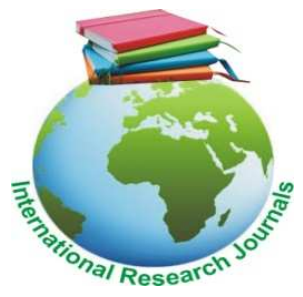

Journal of Medicine and Medical Sciences Vol. 8(6) pp. 077-083, October 2017

DOI: http:/dx.doi.org/10.14303/jmms.2017.085

Available online http://www.interesjournals.org/JMMS

Copyright (C) 2017 International Research Journals

Full Length Research Paper

\title{
Prevalence and pattern of heart diseases in a new tertiary hospital in north central Nigeria: an echocardiographic study
}

\author{
*Okpara Ihunanya Chinyere and Ogiator Monday Ogiagah \\ 'Department of Medicine, P.M.B. 102119, Benue State University Makurdi, Nigeria \\ ${ }^{*}$ Corresponding Author's Email: iokparajubilee@gmail.com
}

\begin{abstract}
Heart diseases occur in all age groups but the prevalence and pattern differs according to age, geographical region and socioeconomic status. Echocardiography is a non-invasive, relatively cheap imaging technique for evaluation of heart disease with reliable levels of accuracy. The aim of this study is to determine the prevalence and pattern of heart disease in our setting using echocardiography. Retrospective analysis of echocardiographic reports of heart diseases was done for age, sex and echocardiographic diagnoses. The mean age of the population was $47.76 \pm 19.45$ years. Males were 122 and females were 109 . Seventy two subjects $(32.1 \%)$ had hypertensive heart disease, $53(22.9 \%)$ had dilated cardiomyopathy, 36(15.6\%) had rheumatic heart disease, $15(6.5 \%)$ had ischemic heart disease, $10(4.3 \%)$ had pericardial diseases, $9(3.9 \%)$ had congenital heart disease, $2(0.9 \%)$ had corpulmonale. Others included 6 isolated right ventricular dilatation, 1 isolated left atrial dilatation and 1 hypertrophic cardiomyopathy in $3.5 \%$. Forty echocardiograms $17.3 \%$ were reported as normal. Hypertensive heart disease was the most prevalent heart disease in this study followed by those due to infections. The rising prevalence of ischemic heart disease shows that Nigeria is undergoing epidemiologic transition. Primary preventive measures, control of blood pressure and early treatment of infections is therefore recommended.
\end{abstract}

Keywords: Heart diseases, Echocardiography, Epidemiologic transition, Nigeria.

\section{INTRODUCTION}

Cardiovascular diseases (CVD) are a major cause of morbidity and mortality worldwide, being responsible for $30 \%$ of all deaths and $10 \%$ of disability adjustable life years (DALYs) (World Health Organization, 2004). Epidemiologic studies have shown that heart diseases are on the increase worldwide especially in low income and developing countries where non-communicable diseases are emerging (Whelton et al., 2004).

In developed countries, heart diseases especially ischemic heart disease is still the leading cause of death followed by cancer (Peterson et al.,2005, Mathers et al.,2009). Other forms of heart disease include hypertensive heart disease, cardiomyopathies, rheumatic heart disease, congenital heart disease, cor-pulmonale and pericardial diseases.
Heart disease develops as a result of complex interaction between genes and the environment (Romanoski et al., 2010; Talmud, 2007; Sing et al., 2003). Heart diseases are a major cause of death being part of the cardiovascular system.

Currently most CVD deaths occur in low and middle income countries of which Nigeria is one and there is growing evidence that an epidemic of CVD is emerging in these countries that must be prevented (Ogun et al., 2000; Chen et al., 2003). There is therefore a need to institute aggressive measures to forestall this epidemic in these countries.

Knowledge of the pattern and prevalence of heart disease in any environment but especially in developing countries is important because as socioeconomic 
situations improve, epidemiologic transitions take place and pattern of disease change. This knowledge is important in health care planning and provision of health care services.

Echocardiography has grown to become the most widely used cardiac imaging technique worldwide. It is a relatively cheap and non-invasive technique with reliable levels of accuracy. Echocardiography commenced at Benue state University Teaching Hospital (BSUTH) Makurdi on $14^{\text {th }}$ May 2013. There is need to establish an accurate pattern of heart diseases in this newly established tertiary centre in North Central Nigeria to compare with studies from other centres in Nigeria. In port-Harcourt being South Southern Nigeria, a more recent study revealed that hypertensive heart disease had the highest prevalence followed by rheumatic heart disease and then dilated cardiomyopathy (James et al., 2012). The same pattern was seen in Abeokuta being South Western Nigeria (Ogah et al 2008). As Nigeria is located in sub-Saharan Africa, one would have expected an infectious cause to rank first. There are very few studies from North Central Nigeria on this subject.

The aim of this study is to determine the prevalence and pattern of heart diseases diagnosed by echocardiography over a period of 4 years (May 2013 to April 2017) in this new centre in Makurdi North Central Nigeria. This will assist in health care planning and institution of primary preventive measures.

\section{MATERIALS AND METHOD}

The study is a retrospective and descriptive study of prospectively collected data. The data was collected at the department of Internal Medicine, Benue State University Teaching Hospital, Makurdi, Nigeria between May 2013 to April 2017.

The centre is a relatively young one established in 2012 by the Federal Government of Nigeria to cater for the health needs of the people Benue state and its environs in North Central Nigeria. The state has a population of about 4.3 million people and a land area of about 13,150 square kilometres. Echocardiography is performed at our centre on a twice weekly basis except in emergency situations. Ethical approval was obtained from the ethical review committee of BSUTH.

\section{Clinical evaluation}

Baseline clinical and demographic characteristics were obtained from the subjects. These include: age, gender, blood pressure and indication for echocardiogram. Weight was measured in kilograms using a weighing scale and height was measured in meters using a stadiometer. The blood pressure was taken with
Accoson's mercury sphigmomanometer in the sitting position after a 5 minutes rest.

\section{Echocardiography}

Two-dimensional targeted M-mode echocardiography with the use of commercially available echo-machine (PHILIPS HD11 XE) and a $2.5 \mathrm{MHz}$ linear array transducer was performed in all subjects in the lateral decubitus position. All measurements were made according to the recommendation of the American Society of Echocardiography (ASE) being the leading edge to leading edge convention (Sahn et al., 1978). Echocardiographic examination was performed in the parasternal long axis, short axis, apical four chamber views and occasionally in the subcostal and suprasternal views. The left ventricular (LV) measurements were obtained at end diastole and end systole in the parasternal long axis views.

The LV measurements taken included the left atrial diameter (LA), aortic root diameter (AO), aortic valve opening (AVO). Others include interventricular septal thickness at end-diastole (IVSd) and end systole (IVSs), the posterior wall thickness at end diastole (PWTd) and end-systole (PWTs), and the LV internal dimensions at end diastole (LVIDd) and end systole (LVIDs). The end of diastole was taken as the peak of the $R$ wave on the echocardiograph while end-systolic measurements were taken at the nadir of the LV septal wall.

All echocardiographic diagnoses were based on standard criteria. Hypertensive heart disease was diagnosed in the presence of any or combination of the following abnormalities: left ventricular hypertrophy [Indexed LVmass > 77.7g/ $\mathrm{m}^{2}$ in males and $>69.8 \mathrm{~g} / \mathrm{m}^{2}$ in females (Schiller et al., 1989), a dilated left atrium, a surrogate of impaired LV filling (left atrial diameter > $4 \mathrm{~cm})$. Rheumatic heart diseases were documented based on the following:

i. Mitral stenosis: Presence of thickened and calcified mitral valve leaflets, loss of classic M-shaped pattern of a normal mitral valve, diastolic dooming and restriction of the mitral valve leaflet motions.

ii. Mitral regurgitation: poor coaptation of the mitral valve leaflets in systole, thickened leaflets, dilated left atrium and hyper dynamic dilated left ventricle, presence of mosaic jet of mitral regurgitation on colour Doppler in apical four chamber view.

iii. Aortic stenosis: Presence of calcified aortic valve, reduction in aortic cusp separation, highly echoes reflectant aortic valve leaflets.

iv. Aortic regurgitation: Poor coaptation of the aortic cusps in diastole dilated left ventricles, fluttering of the anterior mitral valve in diastole. Colour Doppler was used to detect and quantify jet of regurgitation.

Dilated cardiomyopathy was diagnosed when there 
Table 1: Demographic and clinical characteristics of the subjects

\begin{tabular}{lcccc}
\hline Variable & Male $\mathbf{n}=\mathbf{1 2 2}$ Mean(SD) & Female $\mathbf{n}=\mathbf{1 0 9}$ Mean (SD) & t-test & p-value \\
\hline Age & $48.34(20.05)$ & $47.12(18.83)$ & 0.48 & 0.634 \\
Systolic BP & $127.41(23.38)$ & $129.10(22.63)$ & -558 & 0.577 \\
Diastolic BP & $82.11(13.58)$ & $81.29(11.84)$ & 0.491 & 0.624 \\
Height & $1.65(0.20)$ & $1.59(0.14)$ & 2.679 & $0.008^{\star}$ \\
Weight & $69.31(19.81)$ & $68.76(20.22)$ & 0.209 & 0.834 \\
BMI & $\mathbf{2 4 . 9 1 ( 5 . 1 6 )}$ & $\mathbf{2 6 . 7 3 ( 6 . 5 2 )}$ & $\mathbf{- 2 . 3 3 3}$ & $\mathbf{0 . 0 2 1}^{\star}$ \\
\hline
\end{tabular}

$B P=$ Blood pressure, $B M I=$ Body Mass Index,${ }^{*}=$ statistically significant .

Table 2: Age and sex distribution of the population

\begin{tabular}{lccc}
\hline Age group (years) & Male $\mathbf{n = 1 2 2}$ & Female $\mathbf{n}=\mathbf{1 0 9}$ & Total $\mathbf{n}=\mathbf{2 3 1}$ \\
\hline$<20$ & 13 & 8 & 21 \\
$20-29$ & 9 & 12 & 21 \\
$30-39$ & 12 & 16 & 28 \\
$40-49$ & 19 & 16 & 35 \\
$50-59$ & 28 & 26 & 54 \\
$60-69$ & 25 & 15 & 40 \\
$\geq 70$ & 16 & 16 & 32 \\
\hline
\end{tabular}

are dilated heart chambers with normal or decreased wall thickness as well as impaired LV systolic function (World Health Organization, 1984).

Ischemic heart disease was diagnosed in the presence of regional wall motion abnormality involving the left ventricular walls.

Pericardial effusion was diagnosed when there is an echo free space between the visceral and parietal pericardium. Cor-pulmonale was present when there is a dilated and hypertrophied right ventricle (RV) and evidence of increased RV systolic pressure.

\section{Statistical analysis}

Data was analysed using the statistical package for social sciences (SPSS) version 20 statistical soft ware. For quantitative variables, means and standard deviations were calculated and the means compared using the independent samples $t$ test. Qualitative variables were presented as count and percentages. Values of $p<0.5$ were considered statistically significant.

\section{RESULTS}

\section{Demographic and clinical characteristics of the subjects}

During the 4 years under review, 256 echocardiograms were performed. The data of 26 subjects were excluded due to incomplete data. The echocardiograms of two hundred and thirty (231) subjects were analysed.

The demographic and clinical characteristics of the subjects were as follows: there were 122 males and 109 females. The mean age of the males was $48.34 \pm 20.0$ years and that of the females was $47.12 \pm 18.8$ years. There was no significant difference in the mean ages, systolic blood pressure (SBP), diastolic blood pressure (DBP) and weight between the males and females but there was significant difference in the height and body mass index between the two groups. This is shown in Table 1.

The mean age of all subjects was $47.76 \pm 19.5$ years and the age range was $1-90$ years. The population peaked in the $50-59$ age groups. Table 2 shows the age and sex distribution of the subjects.

\section{Indications for echocardiography in the subjects}

Table 3 shows the indications for echocardiography in the subjects. The commonest reason for referral was hypertension and hypertensive heart disease being $54.1 \%$. other reasons for referral include : congestive cardiac failure $(14.7 \%)$, dilated cardiomyopathy $(12.1 \%)$, ischemic heart disease $(6.5 \%)$, rheumatic heart disease $(5.6 \%)$, congenital heart disease $(4.8 \%)$ and pericardial diseases $(2.2 \%)$.

\section{Echocardiographic diagnoses in the subjects}

Out of the 231 subjects, 14 subjects had double diagnoses. Hypertensive heart disease was the commonest echocardiographic diagnosis and it was seen in 72 subjects $(31.2 \%)$. This was followed by dilated cardiomyopathy seen in 53 subjects $(22.9 \%)$. Rheumatic heart disease was seen in 36 subjects (15.6\%), ischemic 
080 J. Med. Med. Sci.

Table 3: Indications for echocardiography in the subjects

\begin{tabular}{llcc}
\hline S/No & Indication & Frequency & Percentage (\%) \\
\hline 1. & Hypertension/Hypertensive Heart Disease & 125 & 54.1 \\
2. & Congestive Cardiac Failure & 34 & 14.7 \\
3. & Dilated Cardiomyopathy & 28 & 12.1 \\
4. & Ischemic Heart Disease & 15 & 6.5 \\
5. & Rheumatic Heart Disease & 13 & 5.6 \\
6. & Congenital Heart Disease & 11 & 4.8 \\
7. & Pericardial diseases & 5 & 2.2 \\
8. & Total & $\mathbf{2 3 1}$ & $\mathbf{1 0 0}$ \\
\hline
\end{tabular}

Table 4: Echocardiographic diagnoses in the subjects

\begin{tabular}{lcccc}
\hline Echocardiographic Diagnosis & Male & Female & Total & Percentage (\%) \\
\hline Hypertensive Heart Disease & 35 & 37 & 72 & 31.2 \\
Dilated Cardiomyopathy & 37 & 16 & 53 & 22.9 \\
Rheumatic Heart Disease & 10 & 26 & 36 & 15.6 \\
Ischemic Heart Disease & 9 & 6 & 15 & 6.5 \\
Pericardial Diseases & 7 & 3 & 10 & 4.3 \\
Congenital Heart Diseases & 6 & 3 & 9 & 3.9 \\
Corpulmonale & 0 & 2 & 2 & 0.9 \\
Others & 4 & 4 & 8 & 3.5 \\
Normal study & 20 & 20 & 40 & 17.3 \\
\hline
\end{tabular}

heart disease in 15 subjects (6.5\%), pericardial diseases in 10 subjects (4.3\%), congenital heart diseases in 9 subjects $(3.9 \%)$, corpulmonale in $2(0.9 \%)$ subjects. Others included 6 cases of isolated right ventricular dilatation, 1 case of hypertrophic cardiomyopathy and 1 case of isolated left atrial dilatation constituting $3.5 \%$ of the subjects. Forty subjects (17.3\%) had normal study. These are shown in Table 4.

The commonest form of pericardial disease was effusive pericarditis present in 9 subjects. Two subjects had pericardial tamponade and constrictive pericarditis was seen in 1 subject.

Congenital heart disease seen was mainly membranous ventricular septal defect in 8 subjects and 1 case of tetralogy of fallot in an adult female. Figures 1 and 2 are examples of documented cases.

\section{DISCUSSION}

The present echocardiographic based study has shown that the common heart diseases in Makurdi, North central Nigeria are hypertensive heart disease, dilated cardiomyopathy and rheumatic heart disease. Ischemic heart disease, pericardial disease, congenital heart disease, cor-pulmonale were less frequently diagnosed.

Hypertensive heart disease is by far the commonest heart disease in this study with a prevalence of $31.2 \%$ (Table 4). This is not surprising as it is a reflection of the rising prevalence of systemic hypertension in Nigeria which is presently put at $22.7 \%$ (Adediran et al., 2013). Furthermore since hypertension is regarded as the silent killer, in an environment like Nigeria where regular medical checkups are not carried out by the generality of the population, it may remain asymptomatic till late and many hypertensive patients are not diagnosed till they present with complications like heart failure, renal failure and stroke. Another reason for the high rate of hypertensive heart disease in this study is the fact that many patients with systemic hypertension, even when diagnosed early may not be able to afford or comply to regular/lifelong antihypertensive therapy resulting in poor drug compliance and accelerated development of hypertensive heart disease. The treatment here includes life style modification, control of hypertension and cardiac muscle remodelling therapy (Ferdinand et al., 2006). 


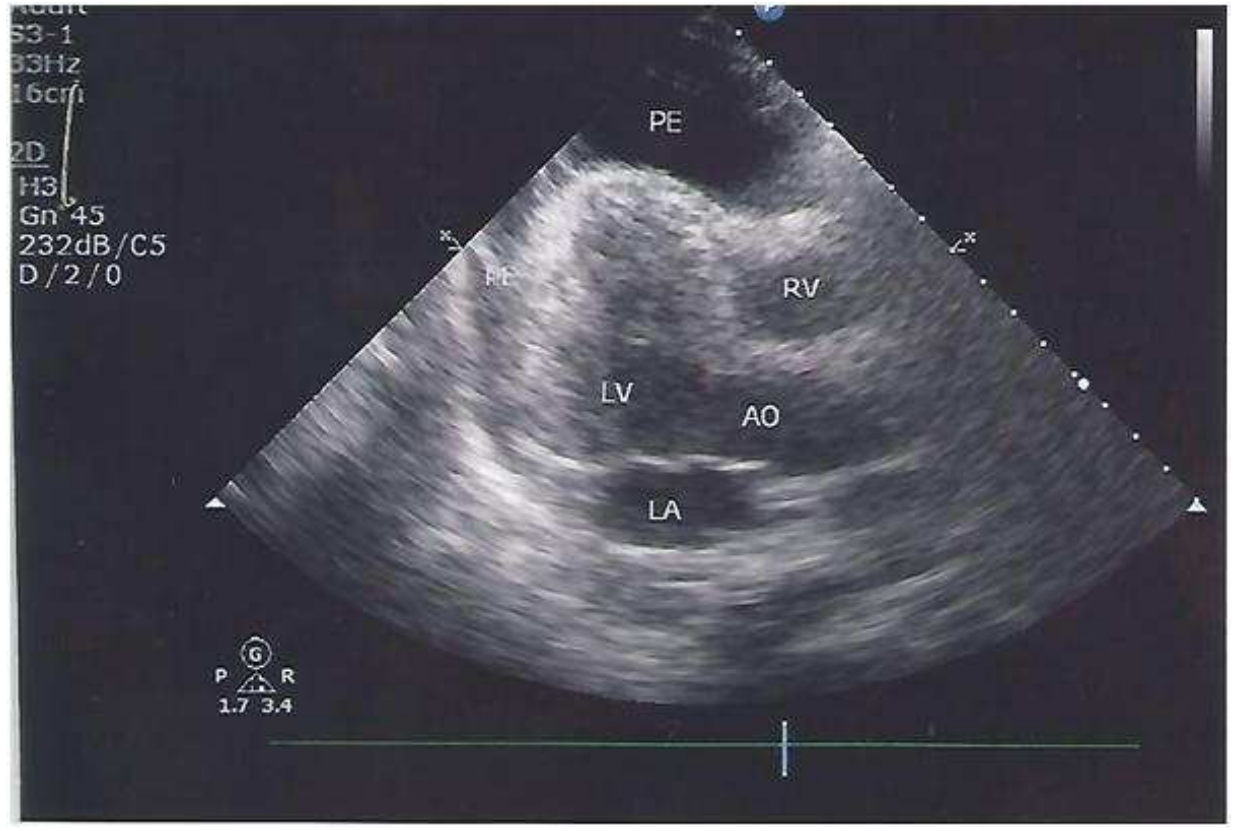

Figure 1: Pericardial Tamponade showing large pericardial effusion(PE) and collapse of anterior wall of right ventricle $(\mathrm{RV})$.

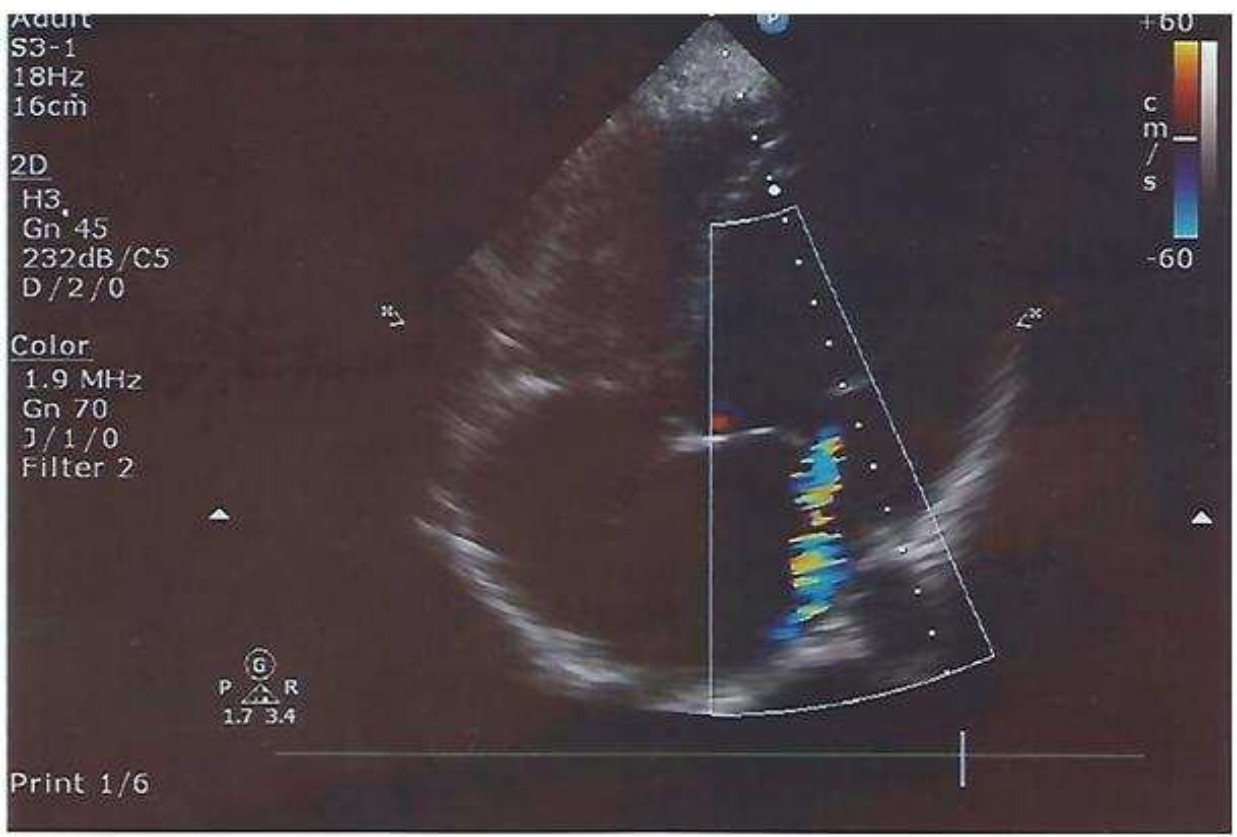

Figure 2: Colour Doppler echocardiography showing mitral regurgitation.

Dilated cardiomyopathy was next to hypertensive heart disease in our study and contributed $22.9 \%$ of cases. This is different from some other studies in Nigeria where rheumatic heart disease ranked second (James et al.,2012, Ogah et al., 2008, Eyo et al., 2015). However our findings are similar to those of Ukoh (Ukoh, 2005) in Benin who reviewed 869 patients referred for echocardiography between January 1992 and May 2001. Hypertensive heart disease (32.7\%), dilated cardiomyopathy (19.2\%), rheumatic heart disease (18.1\%), 
and pericardial diseases $(12.1 \%)$ were the common heart diseases identified. Ischemic heart disease was uncommon $(2.9 \%)$. Fifty eight studies were reported as normal. Similar findings were also documented by Balogun et al. (Balogun et al., 1999) in a preliminary audit of 100 two-dimensional and Doppler echocardiographic service in a tertiary private hospital in Nigeria. Their findings were hypertensive heart disease (53\%), cardiomyopathies $(21 \%)$, valvular heart disease $(7 \%)$, pericardial effusion(4\%) and ischemic heart disease $(2 \%)$. Thirteen percent of their procedure was reported as normal.

Rheumatic heart disease contributed $15.6 \%$ in our study. This shows that rheumatic fever is still of public health importance. One of the cases of rheumatic heart disease had infective endocarditis. The simple improvement in environmental sanitation, personal hygiene and primary health care has a great potential to significantly reduce the incidence of rheumatic fever and its sequel of rheumatic heart disease. This is the reason why the disease is less prevalent in Western Countries (lung and Vahanian, 2014). This preventive approach is more viable than treatment of the sequels of rheumatic heart disease, which include heart valve repair and replacement which are major and expensive procedures not regularly available in most parts of Nigeria at the moment.

Ischemic heart disease was less frequently diagnosed contributing $6.5 \%$ in our study. This is higher than was obtained in other studies in Nigeria (Ukoh, 2005, Balogun et al., 1999). This rising prevalence shows that as socioeconomic status is improving, Nigeria is now in an epidemiologic transition. This is similar to what happened in Indonesia as socioeconomic status improved in that country (Boedhi-Darmojo, 1993). Population screening needs to be instituted to identify important risk factors that have led to this epidemiologic transition and address them.

Effusive pericarditis was the commonest form of pericardial disease seen in 9 subjects. There were 2 cases of pericardial tamponade requiring immediate intervention with therapeutic pericardiocentesis. One subject had constrictive pericarditis and was sent to another centre for pericardiectomy. A previous study done in the Nigerian National Cardiothoracic centre of Excellence proved the accuracy of transthoracic echocardiography as a pericardial diseases diagnostic tool (Ekpe and Anyanwu, 2006).

The low frequency of corpulmonale and hypertrophic cardiomyopathy is similar to other studies (Ogah et al., 2008; Eyo et al., 2015). Congental heart diseases mainly ventricular septal defect was seen mostly in male children and one case of tetralogy of fallot in a female was also seen. The large number of normal studies at echocardiography is similar to other studies in Nigeria (Sani et al., 2007). This can be explained by the fact that the referrals came from all cadre of physicians and most often the subjects were not properly screened before referral.

The potential of echocardiography as a research tool in Nigeria cannot be overemphasized. Studies emanating from the country have focused on the common cardiovascular diseases in the country such as hypertensive heart disease (Adebiyi et al.,2005), dilated cardiomyopathy including peripatum heart disease (Danbauchi, 2002), and valvular heart disease including rheumatic heart disease. Others have also studied cardiac function in diabetes mellitus (Osunkwo and Okeahialam, 2001), chronic renal failure, congenital heart diseases (Sani et al., 2007), mitral valve prolapsed (Oladapo and Falashe 2001), sickle cell disease and normal Nigerians.

\section{CONCLUSION}

This study has identified that hypertensive heart disease, dilated cardiomyopathy and rheumatic heart disease are the commonest causes of heart disease in Makurdi, North central Nigeria. It has also shown a rising trend in ischemic heart disease followed by pericardial diseases.

This shows the increasing burden of noncommunicable diseases as well as infections and infestations which can lead to dilated cardiomyopathy, rheumatic heart disease and pericardial diseases.

There is therefore need to institute population screening to identify cardiovascular risk factors such as hypertension, obesity, smoking and control them.

Improvement in environmental sanitation, personal hygiene and early diagnosis of throat infections and other forms of infection should be carried out to reduce the prevalence of these heart diseases.

\section{REFERENCES}

Adebiyi AA, Aje A, Ogah OS, Ojji DB, Dada A, Oladapo OO, Falase AO (2005). Correlates of left atrial size in Nigerian hypertensives. Cardiovasc J S Afr. 16: 158 - 161

Adediran OS, Okpara IC, Adeniyi OS, Jimoh AK (2013). Hypertension prevalence in an urban and rural area of Nigeria. 4: 149-154.

Balogun MO, Urhoghide VA, Ukoh VA, Adebayo RA (1999). A preliminary audit of Two-Dimensional and Doppler Echocardiographic Service in a Nigerian Tertiary Private Hospital. Nig J Med. 8: 139 - 141.

Boedhi-Darmojo R (1993). The pattern of cardiovascular disease in Indonesia. World Health Stat Q. 46(2): 119-124.

Cardiomyopathies. Report of a WHO Expert committee. World Health Organ Tech Rep Ser (1984). 697: 7 - 64.

Chen HZ, Fan WH, Jin XJ, Wang Q, Zhou J, Shi ZY (2003). Changing trends of etiologic characteristics of cardiovascular diseases amongst in patients in Shanghai: a retrospective observational study from 1948 to 1999. Zhonghua Nei Ke Za Zhi. 42(12): $829-832$.

Danbauchi SS (2002). Echocardiographic features of peripartum cardiac failure: the Zaria syndrome. Trop Doct. 32: $24-27$.

Ekpe EE, Anyanwu CH (2006). Accuracy of Trans-thoracic echocardiography as a pericardial diseases diagnostic tool. Ibom Med J. 1: $1-4$.

Eyo EE, Mandu Cl, Idongesit U (2015). Echocardiographic pattern of 
acquired heart diseases in Nigeria. Niger Med. J. 56(4): 253 - 257.

Ferdinand KC, Saunders E (2006). Hypertension related morbidity and mortality in African Americans - Why we need to do better. J Clin Hypertens (Greenwich). 8 (1 Suppl 1): $21-30$.

lung B, Vahanian A (2014). Epidemiology of acquired valvular heart disease. Can J Cardiol. 30: $962-970$.

James OO, Efosa JD, Romokeme AM, Zuobemi A, Sotonye DD (2012). Dominance of hypertensive heart disease in a tertiary hospital in Southern Nigeria: an echocardiographic study. Ethn Dis Spring. 22(2): $136-139$

Mathers CD, Boerma T, Fat DM (2009). Global and regional causes of death.Br Med Bull. 9(1): $7-32$.

Ogah OS, Adegbite GD, Akinyemi RO, Adesina JO, Alabi AA, Udofia OI, Ogundipe RF, Osinfade JKL (2008). Spectrum of heart diseases in a new cardiac service in Nigeria: An echocardiographic study of 1441 subjects in Abeokuta. BMC Res Notes. 1: 98 - 104

Ogun SA, Adelowo OO, Familoni OB, Jaiyesimi AE, Fakoya EA (2000). Pattern and outcome of medical admissions at Ogun State University Teaching Hospital, Sagamu-a three year review. West AfrJ Med. 19: $304-308$.

Oladapo OO, Falase AO (2001). Prevalence of mitral valve prolapse in healthy young Nigerians as diagnosed by echocardiography. Afr J Med Med Sci. 30: $13-16$.

Osunkwo DA, Okeahialam BN (2001). Left ventricular function in Nigerian Africans with non-insulin-dependent diabetes mellitus. Am J Cardiol. 87: 1026 - 1029.

Petersen S, Peto V, Rayner M, Leal J, Luengo-Fernandez R, Gray A (2005). London: British Heart Foundation. European Cardiovascular Disease Statistics.

Romanoski CE, Lee S, Kim MJ, Ingram-Drake L, Plaisier CL, Yordanovu $R$ (2010). Systems genetics analysis of gene-byenvironment interactions in human cells. Am J Hum Genet. 86 (3): $3399-3410$
Sahn DJ, DeMaria A, Kisslo J, Weyman A (1978). Recommendations regarding Quantitation in M-mode Echocardiography. Results of a survey of Echocardiographic measurements. Circulation. 56: 1072 1083.

Sani MU, Karaye KM, Ibrahim DA (2007). Cardiac morbidity in subjects referred for echocardiographic assessment at a tertiary medical institution in the Nigerian Savannah zone. Afr J Med Med Sci. 36: $141-147$.

Sani MU, Mukhtar-Yola M, Karaye KM (2007). Spectrum of congenital heart disease in a tropical environment: an echocardigraphic study. J Natl Med Assoc. 99: 665 - 669.

Schiller NB, Shah PN, Crawford M (1989). Recommendations for quantitation of the left ventricular mass by two dimensional echocardiography. J Am Soc. Echocardiography. 2: 258 - 269.

Sing CF, Stengard JH, Kardia SL (2003). Genes, environment, and cardiovascular disease. Arterioscler Thromb Vasc Biol. 23: 1190 1196.

Talmud PJ (2007). Gene-environment interaction and its impact on coronary heart disease risk. Nutr Metab Cardiovasc Dis. 17(2): 148 $-152$.

Ukoh VA (2005). Spectrum of heart diseases in adult Nigerians: an echocardiographic study. Nigerian Journal of Cardiology. 2: $24-27$.

Whelton PK, Brancati FL, Appel LJ, Klag MJ (2004). The challenge of hypertension and atherosclerotic cardiovascular disease in economically developing countries. High Blood Press. 4 : $36-45$.

World Health Organization. The global burden of disease: 2004update. Available at http://www.who.int/healthinfo/global burdendisease/ 2004 report_update/en/index.html (assessed December $2^{\text {nd }}, 2010$. 